\title{
Een overtollig mens
}

Citation for published version (APA):

van der Linden, J. M. J. P. (2013). Een overtollig mens: Afscheidsrede van Prof. Dr. J.M.J.P. van der Linden. (1 ed.) Universiteit Maastricht. https://doi.org/10.26481/spe.20131213jl

Document status and date:

Published: 13/12/2013

DOI:

10.26481/spe.20131213jl

Document Version:

Publisher's PDF, also known as Version of record

\section{Please check the document version of this publication:}

- A submitted manuscript is the version of the article upon submission and before peer-review. There can be important differences between the submitted version and the official published version of record.

People interested in the research are advised to contact the author for the final version of the publication, or visit the DOI to the publisher's website.

- The final author version and the galley proof are versions of the publication after peer review.

- The final published version features the final layout of the paper including the volume, issue and page numbers.

Link to publication

\footnotetext{
General rights rights.

- You may freely distribute the URL identifying the publication in the public portal. please follow below link for the End User Agreement:

www.umlib.nl/taverne-license

Take down policy

If you believe that this document breaches copyright please contact us at:

repository@maastrichtuniversity.nl

providing details and we will investigate your claim.
}

Copyright and moral rights for the publications made accessible in the public portal are retained by the authors and/or other copyright owners and it is a condition of accessing publications that users recognise and abide by the legal requirements associated with these

- Users may download and print one copy of any publication from the public portal for the purpose of private study or research.

- You may not further distribute the material or use it for any profit-making activity or commercial gain

If the publication is distributed under the terms of Article $25 \mathrm{fa}$ of the Dutch Copyright Act, indicated by the "Taverne" license above, 
Prof.Dr. J.M.J.P. van der Linden

Faculty of Health, Medicine and Life Sciences

\section{Een overtollig mens}


Een overtollig mens 


\section{Colofon}

Design \& print: Canon Business Services, Maastricht

ISBN: 9789056814496

NUR: 870

All rights reserved. No part of this publication may be reproduced, modified, stored in a retrieval system or made public without the prior written permission of the author or publisher. 


\section{Een overtollig mens}

Afscheidsrede Professor JMJP (Sjef) van der Linden als hoogleraar Reumatologie aan de Universiteit van Maastricht.

Maastricht, datum 13 december 2013

Door Prof.Dr. J.M.J.P. van der Linden 
Een overtollig mens 
Mijnheer de Rector Magnificus,

Dames en Heren,

Welkom geachte aanwezigen bij mijn afscheidsrede op vrijdag de $13^{\mathrm{e}}$ December, niet toevallig mijn $69^{\mathrm{e}}$ verjaardag. Vooral aan de bijgelovigen onder $u$ betuig ik waardering voor uw moedige komst.

Belangenverstrengeling bedreigt in de geneeskunde de waarde van publicaties en voordrachten. Daarom allereerst mijn "disclosures". Ik werd als "Ambtenaar in de Gezondheidszorg" (Rosalie Sprooten) al meer dan 26 jaar financieel ondersteund door het MUMC met een prima salaris ruim onder de Balkenende norm. Verder ondervond ik steeds steun van mijn vrouw Hermine.

Een afscheidsrede, wat is dat eigenlijk? Het beslaat een periode van vele jaren, ruim 26 in mijn geval. Er gaan maanden van voorbereidend denken aan vooraf. Het krijgt vorm in enkele weken en wordt uitgesproken op 1 dag binnen 1 uur ofwel 60 minuten. In het beste geval herinnert u zich later hooguit enkele seconden.

Een afscheidsrede is in Maastricht een merkwaardig fenomeen, gekenmerkt door typisch eenrichtingsverkeer. Immers, u zit - al dan niet uit belangstelling of uit plichtsbesef - te luisteren of weg te dutten, maar uw rol is in elk geval passief, terwijl alleen activiteit van mijn kant verwacht wordt. Kortom, er is geen interactie. Dat laatste, interactie, zou je nu juist wel verwachten in het Maastrichtse onderwijssysteem. Overigens wordt hier vaak verhuld dat wat het Maastrichtse onderwijs systeem genoemd wordt zijn oorsprong niet hier ter stede heeft, maar uit Canada, uit de McMaster Universiteit (Evans) afkomstig is, waar ik van 1986-1987 heb mogen verblijven voor training in de klinische epidemiologie. Dit op initiatief van mijn grote leermeester op dat terrein Hans Valkenburg. Overigens werd hij daarvoor niet beloond. In november 1987 keerde ik (tot zijn aanvankelijke teleurstelling) niet terug naar de Erasmus Universiteit te Rotterdam, maar startte ik als hoogleraar reumatologie in Maastricht.

Niet op initiatief van de faculteit geneeskunde, noch op dat van het AZM in die jaren, maar op initiatief van de vader der academische Interne Geneeskunde in Maastricht, de helaas te vroeg gestorven Guus Flendrig, kwam het, mede mogelijk gemaakt door het toenmalige beleid van het Nationaal Reumafonds (NRF), tot het instellen van een (bijzondere) leerstoel in de reumatologie. Het NRF faciliteerde destijds het instellen 
van een leerstoel reumatologie aan elke medische faculteit in Nederland. De leerstoel werd door het NRF financieel gesteund voor het verrichten van onderzoek. Die steun, waardoor ook succesvol andere bronnen konden worden aangeboord, bleef tot het jaar 2013 gehandhaafd. Door nieuw (nieuw is niet altijd beter) beleid van het NRF ontberen nu in schaarse tijden Groningen, Twente en Maastricht (dus een groot deel van Noord-, Oost- en Zuid Nederland) deze steun. Het resultaat hiervan zal zijn, dat voor het NRF de concurrentie bij de fondsenwerving zal toenemen, omdat deze centra nu zelf fondsenwerving zullen entameren.

Op wie moet een afscheidsrede zich richten? Op collegae of op een breder publiek waaronder patiënten? Keep it simple, iets voor allen wellicht van heden, verleden en toekomst in schaarse tijden.

Een belangrijk aspect van een afscheidsrede - naast de inhoud - is de keuze van een titel. Hier volgen titels die afgevallen zijn, maar toch een deelaspect verraden:

- Oud en Nieuw, van alles wat (Tom Ehrlich - AVRO)

- Van A tot S (ofwel de Unvollendete, namelijk onvoltooid Ankylosing Spondylitis onderzoek)

- De Professor vertelt

- De professor vertelt verder

- De Professor kan me nog meer vertellen

- It is time to say goodbye!

- Non, je ne regrette rien (E. Piaf)

- New York, New York (F. Sinatra): "bestseller" publicatie met hoge Scientific Citation Index: modified New York Criteria for Ankylosing Spondylitis

- I did it my way (F. Sinatra)

- Onder Moeders Paraplu? (Reumatologie in Maastricht binnen de afdeling Interne Geneeskunde)

- Veni, Vidi, Foetsji (Emeritaat)

- Van Oude Menschen De Dingen Die Voorbij Gaan (Couperus)

Er spreekt enige ambivalentie uit deze titels over afscheid nemen en met emeritaat gaan, doch een verlenging ("naspeeltijd") van 4 jaar na het $65^{\text {ste }}$ gaf mij tijd enigszins aan het idee te wennen en beschermde mij vooralsnog tegen significante inzet thuis in onze (te) grote tuin. 
De definitieve keuze is geworden: Een Overtollig Mens.

Waar slaat dat op? Is het een, wellicht wat late maar niettemin adequate, uiting van zelfreflectie? Dat is niet het geval.

Een andere interpretatie door sommigen verondersteld vanwege een mogelijke gelijkenis met bestaande gebeurtenissen, is eveneens onjuist, maar ik noem die $u$ niettemin. Het zou te maken hebben met "ombuigingen" en "boventalligheid." Dat zijn uitdrukkingen, die zoals u weet, een eufemisme vormen voor "bezuinigingen." Als een boventallig verklaarde persoon van geen wijken weet en handig weet te manoeuvreren en de media handig bespeelt, kan een situatie van tolerantie ontstaan, een soort immunotolerantie. Zeker wanneer men niet graag in de kijker wil komen.

Waar slaat de titel "Een Overtollig Mens" dan wel op? De titel refereert aan een boekenweek geschenk uit de vorige eeuw van de schrijver Maarten Biesheuvel. Daar ligt de sleutel tot ofwel het "Leitmotiv" voor veel onderzoek van de afscheidnemend hoogleraar. Zoals $u$ zult zien kunnen we Leitmotiv haast gelijkstellen met gemotiveerd door het lijden van patiënten met reumatische aandoeningen. Op deze plaats werd tijdens de afscheidsrede een video vertoond waarop het echtpaar Biesheuvel aan het woord is. De echtgenote van dhr. J.M.A. (Maarten) Biesheuvel lijdt aan een ernstige vorm van de ziekte van Bechterew (spondylitis ankylopoëtica). De schrijver Maarten Biesheuvel beschrijft in zijn boek getiteld "Een Overtollig Mens" een patiënte B. Dat boek was het boekenweekgeschenk in 1988. Maarten Biesheuvel noemt patiënte B. op andere plaatsen Eva. Deze Eva heeft een HLA-B27 negatieve ziekte van Bechterew. Zij is één van de patiënten in mijn Leids familie onderzoek en als zodanig opgenomen in mijn proefschrift (1982). In meerdere opzichten was het een familie onderzoek. Mijn vrouw - Hermine ondersteunde mij (ook toen al) bij organisatie en administratie. Dat alles in een tijd zonder computers met tekst- of dataverwerking. Echt handwerk dus.

Hoe kwam het überhaupt tot familie (en later tot ook bevolkingsonderzoek) van Morbus Bechterew?

De Oostenrijkse schrijver Stefan Zweig heeft het in zijn historische romans als "Marie-Antoinette", "Maria Stuart" of "Die Welt von Gestern" regelmatig over "die eine entscheidende Sekunde", dat ene moment, die 
ene beslissing, die ene gebeurtenis, die een heel leven en dat van vele anderen totaal beïnvloeden kan. Dat is hier ook het geval.

Op zekere dag, kort nadat in 1973 zowel in de New England Journal of Medicine als in The Lancet de allereerste publicaties over de associatie tussen de genetische factor HLA-B27 en Morbus Bechterew verschenen waren, besprak ik dit ergens in de gang op weg naar een patiënt met Professor Cats (zodra je specialist was mocht je hem Nol noemen, maar zover was ik toen als assistent nog niet). Na het lezen van het letterlijke monniken werk van Mendel over zijn experimenten met groene en gele erwten in het boek "100 jaar Mendel" had ik nog meer belangstelling voor genetica gekregen. Ik stelde Professor Cats voor promotie onderzoek te gaan doen naar de rol van HLA-B27, gezien het familiair voorkomen van Morbus Bechterew. Zijn antwoord was zeer positief. (Mij kennende zal hij vermoed hebben dat een negatief antwoord niettemin hetzelfde effect gehad zou hebben).

Daarmee was "Bechterew" als Leitmotiv voor onderzoek, dat door mij van 1982-1986 voortgezet werd aan de Universiteit van Bern en dat daarna steeds centraal stond binnen het reumatologisch onderzoek in Maastricht, geboren.

Overigens heb ik Mendel vaak benijd. Immers, voor zijn onderzoek met erwten hoefde hij, anders dan thans voor patiëntgebonden onderzoek zelfs voor de meest simpele vraagstellingen geen toestemming te vragen (in 17-voud) bij een medisch ethische commissie, een ware papier winkel.

Kort samengevat bleek dat 1 op de 5 (20\%) HIA-B27+ (eerstegraads) verwanten van (HLA-B27+) Bechterew patiënten ook dergelijke verschijnselen vertonen. Dit is in grote lijnen conform eerder Gronings onderzoek uit het pre-HLA tijdperk, maar strijdig met bevindingen in de zeventiger jaren bij bloeddonoren door onderzoekers elders. Dat leverde enkele polemieken op in The Journal of Rheumatology. Onbevestigd is het gerucht dat toentertijd door die polemiek de oplage van dat tijdschrift sterk is gestegen.

Er bleek sprake van "overreading" door die andere onderzoekers. Zij zagen afwijkingen op röntgenfoto's van sacroiliacale gewrichten waar die redelijkerwijze niet aanwezig konden zijn. Epidemiologisch gesproken gaat het daarbij om de begrippen sensitiviteit en specificiteit. 
Dat zijn begrippen die vaak aanleiding geven tot verwarring. Een voorbeeld kan die begrippen snel verhelderen.

Het EPOZ bevolkingsonderzoek bij ruim 3000 inwoners van Zoetermeer liet zien dat het risico voor HLA-B27 positieve personen in de bevolking veel lager is: $1-3 \%$. In families spelen naast HLA-B27 ook andere genen een rol postuleerden wij. Dit is inmiddels met modern genetisch onderzoek (GWAS) bevestigd.

Lange tijd werd de aanwezigheid van radiologische sacroiliitis beschouwd als een "conditio sine qua non" voor Morbus Bechterew. Meer recent ontstond het concept "axiale spondyloarthritis (SPA)." Dat begrip omvat ook Morbus Bechterew zonder radiologische sacroiliitis. Echter ook hier zijn er problemen met betrekking tot specificiteit. Van dergelijke patiënten mag men verwachten dat zij genetisch sterk zullen lijken op de klassieke Bechterew patiënten die voldoen aan de "modified New York criteria". Deze patiënten kunnen net zoveel last hebben van de reumatische ontsteking als de klassieke Bechterew patiënten en zij verdienen gelijke adequate behandeling. Toch is er een probleem, niet zozeer met het concept, als wel met de nieuwe criteria voor het concept axiale SpA. Zelfs wanneer in één en hetzelfde land zogenaamde experts patiënten als axiale SpA bestempelen, blijkt er een enorme genetische heterogeniteit te bestaan. Als voorbeeld het volgende: de HLA-B27 frequentie varieert van $20 \%$ bij de ene expert tot $80 \%$ bij een andere expert in hetzelfde land. Er zijn blijkbaar "look-alikes". Criteria voor axiale SpA zijn vaak fout-positief en misleidend. Zij verleiden tot het ten onrechte voorschrijven van zeer dure biologicals (TNF-blokkers) die ook risico's opleveren voor de gebruikers. In dit verband is vermeldenswaard dat de Amerikaanse Food and Drug Administration (FDA) deze middelen niet goedgekeurd heeft voor patiënten met niet-radiologische axiale SpA. Tegelijk is vooralsnog onvoldoende uitgezocht of de gewone en veel goedkopere antireumatica (de zogenaamde conventionele DMARDs) bij deze "look-alikes" niet minstens evengoed werken. Er is een enorme push gaande bij iedere patiënt, die aan die onvoldoende gevalideerde criteria voor axiale SpA voldoet, deze dure biologicals voor te schrijven. Het verwijt van belangenverstrengeling geldt sommige professionals en ook farmaceutische bedrijven. De FDA stelt zich kritischer op dan de Europese EMEA. Het gezegde "Wiens luxe brood men eet, diens woord men spreekt" dringt zich hier op. 
Het Maastrichtse Bechterew onderzoek is veel omvattend geweest.

Te omvattend - gelukkig - om het hier geheel uiteen te zetten. Elke poging daartoe zou onrecht doen aan de desbetreffende onderzoekers. Mijn dank - zonder namen te noemen - gaat naar hen allen uit. Hun inzet en motivatie was voortreffelijk.

Het vervult mij met een zekere trots dat 5 medewerkers tijdens mijn ambtsperiode hoogleraar zijn geworden (4 maal in Maastricht). Ik hecht hier aan het woord tijdens, want ik wil beklemtonen dat zij dat terecht bereikten op basis van hun eigen kwaliteit en inzet. Ik beschikte niet over een toverstokje. Wel kon ik hen ruimte geven om zich te ontwikkelen. In chronologische volgorde:

- Maarten Boers (hoogleraar klinische epidemiologie VUMC)

- Desirée van der Heijde (thans hoogleraar reumatologie LUMC)

- Robert Landewé (thans hoogleraar reumatologie UvA)

- Piet Geusens (nu honorair hoogleraar reumatologie MUMC)

- Annelies Boonen (hoogleraar reumatologie MUMC en nieuw afdelingshoofd samen met Dr. Debby Vosse (duale leiding)

Het vertrek uit Maastricht van Desirée van der Heijde en later Robert Landewé beschouw ik niet als hoogtepunten in mijn carrière.

Het absolute dieptepunt in Maastricht was het overlijden van een jonge assistent in opleiding aan een kwaadaardige tumor. Dit gebeurde onder wel zeer dramatische omstandigheden. De tumor openbaarde zich tijdens haar tweede zwangerschap bij Diana Kortenoeven. (Vermelding van haar naam geschiedt met instemming van de familie). De bekkenpijn berustte op een nauwelijks te beïnvloeden maligniteit. Het Echo onderzoek kondigde zowel nieuw leven als de naderende dood aan.

Vooraleer ik verder inga op Bechterew onderzoek, ga ik met u naar Rusland en wel naar het Rusland van de $19^{\mathrm{e}}$ eeuw. Daar leefde van 1857 - 1927 de neuroloog-psychiater Wladimir Michailowitsch Bechterew. Een man van principes. Hij beschreef als één der eersten (hoewel dit niet heel zeker is) Morbus Bechterew. Er zijn aanwijzingen dat hij een andere aandoening beschreef en dat Morbus Bechterew in feite "Die Krankheit mit dem falschen Namen" is. Pierre-Marie (Frankrijk) en Adolf Strümpell (Duitsland) hebben met zekerheid in die periode de correcte diagnose spondylitis ankylopoetica (een synoniem voor Morbus Bechterew) gesteld. Het liep overigens niet goed af met de alom geroemde en beroemde Wladimir Michailowitsch Bechterew. Joseph Stalin ontbood 
hem voor een consult bij zich. Dat 3 uur durende consult vond plaats op 23 december 1927. Hij stelde bij Stalin de diagnose paranoia. Enkele uren later kreeg de tot dan toe volstrekt gezonde Bechterew maagklachten. De volgende dag overleed hij. Er zijn sterke aanwijzingen dat hij vergiftigd werd. Eerst in de periode van destalinisatie komt men zijn naam weer regelmatig tegen. In 1974 kreeg zijn graf in wat toen nog heette Leningrad een standbeeld.

Wat betreft het verdere Bechterew onderzoek in Maastricht volsta ik met het noemen van enkele grote lijnen. In het bijzonder hebben we aandacht besteed aan niet-farmacologische therapie. Oefentherapie bij Bechterew is effectief. Het betreft daarbij de beweeglijkheid, het gevoel van fitheid en het dagelijks functioneren. Dat geldt vooral wanneer dat in groepsverband getraind wordt en met name dan wanneer dat (in Oostenrijk) als een spa-kuur therapie aangeboden wordt. De effecten houden tot minstens 9 maanden aan (in tegenstelling tot vakantie effecten, waarbij de halfwaarde tijd vaak minder dan 1 week bedraagt). Om een idee te geven: de effecten zijn vergelijkbaar met datgene wat met pijnstillende ontstekingsremmende middelen (NSAIDs) bereikt kan worden. Bovendien treedt kostenbesparing op (minder pijnstillers en minder bezoeken aan het ziekenhuis). De overheid en verzekeraar zouden er goed aan doen voorzichtiger om te springen met schrappen van nonfarmacotherapie, waaronder fysiotherapie, uit het basis- of aanvullende zorgverzekeringspakket. Anderzijds zouden de professionals zich best wel sterker mogen maken ("Iobbyen") effectieve non-farmacologische interventies in het verzekerde pakket te behouden.

Ook op farmacologisch gebied hebben we een belangrijke bijdrage kunnen leveren. De farma-industrie zag aanvankelijk geen heil in het onderzoeken bij de ziekte van Bechterew van de werkzaamheid van de bij reumatoïde artritis (RA) zo succesvolle (dure) TNF-blokkers. "Bechterew" was nauwelijks bekend bij de farma-industrie en het aantal patiënten werd als te gering ingeschat. Er bestonden echter nog weinig of geen ziekte-modificerende geneesmiddelen voor Morbus Bechterew. Op niet geheel legale wijze hadden wij echter toch al een behoorlijke ervaring met anti-TNF middelen kunnen opbouwen bij Bechterew patiënten. Zij reageerden bijna zonder uitzondering uitstekend. Hun levenskwaliteit ging met sprongen vooruit. De nieuwe medicijnen werkten bij Bechterew uitstekend, beter nog dan bij RA. Dit vernieuwend oprekken en soms overschrijden van bestaande grenzen en indicatiestellingen acht ik een 
essentiële taak van academische afdelingen.

Die taak wordt er bij krappe budgetten en toenemende regelgeving niet makkelijker op: "Academia let op Uw Saeck!"

Na discussies met en het opstellen onzerzijds van een "Position Paper" ging de betreffende internationale firma overstag. De bottom-up benadering had gewerkt. Dit is een voorbeeld van goede samenwerking met de farmaindustrie. Ook dat mag wel eens gezegd worden. Het betreffende middel is inmiddels al vele jaren ook voor Morbus Bechterew geregistreerd en heel veel Bechterew patiënten ondervinden er veel baat bij. Dit tegen aanvaardbare bijwerkingen (de kans op infecties verdubbeld), maar wel tegen hoge monetaire kosten. Dat is het dramatische van "Cure \& Care" in de gezondheidszorg. Naarmate de geneeskunde meer kan bieden, wordt de gezondheidszorg duurder, ja mogelijk zelfs onbetaalbaar. Zo'n vaart hoeft het echter niet altijd te lopen. Maarten Boers - toen nog in Maastricht - heeft dat met zijn befaamde COBRA onderzoek (COBRA staat voor Combinatietherapie bij Reumatoïde Artritis) aangetoond. Wanneer je namelijk een aantal goedkope traditionele antireumatica combineert, is het effect daarvan veelal even goed als dat van de dure nieuwe middelen, de zogenaamde biologicals. Dit is recent weer eens bevestigd, nu in Amerikaans geïnitieerd onderzoek. Helaas wordt in de dagelijkse praktijk combinatie therapie onvoldoende vaak ingezet. De lobby hiervoor is minder sterk dan die van de farma-industrie.

Wij kunnen thans niet alleen Bechterew patiënten, maar een breed scala van patiënten met inflammatoire reumatische aandoeningen, zoals RA en artritis psoriatica, veel meer levenskwaliteit bieden dan in 1987. Indertijd stapte ik binnen als verse hoogleraar in een mini-afdeling reumatologie als een onderafdeling van de afdeling interne geneeskunde. Die onderafdeling was feitelijk opgezet door Marijke van Santen-Hoefft. Er was 1 assistent en nog geen opleiding tot reumatoloog. Bij mijn vertrek zijn er 9 stafleden (vol- of deeltijds), 4 (uitstekende) assistenten in opleiding, ongeveer 20 promovendi-onderzoekers, alsmede 3 toegewijde secretaresses.

Er is een schaarste aan reumatologen in Nederland. Dat merken we in Limburg heel duidelijk. We streven naar een team dat zorg kan bieden aan heel de provincie. De visie is een samenwerking met alle Limburgse reuma-afdelingen te realiseren. De gezondheidszorg in Nederland wordt gekenmerkt door een (te) scherpe scheiding tussen de eerste- en tweedelijn. Nederland beschikt over een uitstekende gezondheidszorg in de eerste lijn. Toch maakt de te sterke scheiding de zorg onnodig duur 
en uiteindelijk mogelijk onbetaalbaar.

In het Zuid-Limburgse carrouselmodel geven (onder andere) reumatologen op verzoek van de huisarts in een gezamenlijk consult met meerdere huisartsen in hun eigen praktijk en in aanwezigheid van de patiënt advies over diagnose en behandeling. Daarbij onderzoeken ze die patiënten op dat moment ook zelf samen met de huisarts. Wat blijkt? Er is minder aanvullende diagnostiek nodig en de patiënt hoeft meestal niet meer verwezen te worden naar het duurdere ziekenhuis. De zorg wordt efficiënter, goedkoper en leuker. Dit is een voorbeeld van wat tegenwoordig heet anderhalfdelijns-zorg. Deze weg moeten wij verder ontwikkelen. Wij hebben reumatologen nodig die zich goed thuisvoelen in de $2^{\mathrm{e}}$ en $3^{\mathrm{e}}$ lijns zorg, maar ook reumatologen die goed kunnen functioneren (het woord opereren zou hier verwarrend werken) in de $2^{\mathrm{e}}$ en $1 \frac{1}{2} 2^{\mathrm{e}}$ lijn. Dat kunnen - maar hoeven niet - dezelfde personen te zijn. Een deel van de werkzaamheden kan intramuraal zijn, een ander deel extramuraal. Van belang voor de reumatologie acht ik dat de opleiding binnen of althans annex aan een afdeling interne geneeskunde plaatsvindt. Dit is in Maastricht zeker het geval. Ik heb mij steeds en met succes gekant tegen het opheffen van het zelfstandig specialisme reumatologie. In plaats daarvan zou het een aandachtsgebied worden van de interne geneeskunde. Sommigen menen dat ik - toen de discussie binnen de beroepsvereniging op dit punt actueel was - door mijn schriftelijke interventie deze ontwikkeling zelfs geblokkeerd heb. Dat lijkt mij wat veel eer. Juist is dat naar mijn mening aan het opheffen van het specialisme reumatologie aanzienlijke risico's verbonden waren, namelijk het opschuiven in de richting van meer $2^{\mathrm{e}}$ en $3^{\mathrm{e}}$ lijnszorg, in plaats van een beweging naar de $1^{\mathrm{e}}$ lijn $\left(1 \frac{1}{2^{\mathrm{e}}}\right.$ lijnszorg). Het is opvallend dat de gezondheidszorg primair bepaald wordt door wat de zorgverleners aanbieden en niet door wat op basis van het voorkomen (in de zin van incidentie en prevalentie) van klachtenen ziektepatronen op populatie niveau wenselijk zou zijn. De ZORG is grotendeels AANBOD, maar niet VRAAG gestuurd georiënteerd. Ik denk hier in het bijzonder aan het grote volume aan zogeheten weke-delen reumatische klachten (voorbeeld fibromyalgie). Het ware wenselijk dat de expertise voor behandeling en begeleiding met name daar ligt waar de prevalentie hoog is. Dat is het geval in de eerste- en anderhalve lijn. Dat zou dure verwijzing naar intramuraal moeten voorkomen. Dat creëert dan tevens voldoende intramurale ruimte om de expliciete daar aanwezige meerwaarde van een medisch specialist tijdig aan bod te laten komen zonder onaanvaardbaar lange toegangstijden. 
Het gevaar dreigt nu dat $\mathrm{u}$ - met een schuin oog naar de klok - gaat denken: "de professor kan me nog meer vertellen". Kortom, we moeten naar de receptie gaan toewerken.

$\cup$ krijgt dan ruimschoots de mogelijkheid SPA te drinken. SPA staat behalve voor mineraal water - voor SPondyloArtritis, dat wil zeggen de groep van aandoeningen waarvan Spondylitis Ankylopoëtica ofwel Morbus Bechterew de belangrijkste vertegenwoordiger is, het "Leitmotiv" immers van het Maastrichts reumatologisch onderzoek. Echter, we hebben ons ook gestort op de meest voorkomende en naar alle waarschijnlijkheid steeds vaker voorkomende vorm van ontstekingsreuma: jicht. Een ziekte waarbij de herhaalde acute aanvallen van gewrichtsontsteking (vaak in de grote teen) zeer pijnlijk zijn en waarbij op de duur ophopingen (tofi genaamd) van urinezuur kristallen in de huid of in gewrichten tot ernstige beschadiging en zelfs tot invaliditeit kunnen leiden. In wezen echter is jicht goed te behandelen en zijn die gewrichtsbeschadigingen en de daarmee samenhangende invaliditeit bij juiste en tijdige diagnostiek en goede behandeling geheel te voorkomen. De patiënt moet dan evenwel niet stoppen met het innemen van de medicijnen zodra de acute aanval voorbij is. In de praktijk gaat dat om allerlei redenen vaak mis. Bijna de helft (40\%) van alle jicht patiënten die wij zien, hebben die onnodige urinezuur ophopingen (tofi). Voedingsmiddelen spelen daarbij een belangrijke rol. De drank waar Limburg zo trots op is (bier), is een aanzienlijke risicofactor voor jicht aanvallen. Dit geldt echter ook voor fructose (een suiker) bevattende frisdrank. Ja, het geldt tot op zekere hoogte ook voor fruit. Het gezegde: "An Apple A Day Keeps The Doctor Away" zouden we moeten wijzigen in: "An Apple A Day May Not Keep The Rheumatologist Away." De ongunstige rol van suiker, met name fructose - de helft van onze gewone suiker bestaat uit fructose - lijkt als je de medische literatuur bekijkt, een nieuwe bevinding. Toch is dat niet waar. Een landgenoot collega S. Blankaarts heeft dat in 1683 reeds in Amsterdam gepubliceerd in zijn boek "BORGERLIJKE TAFEL om lang zonder Ziekten Gezond te Leven." Hij beschrijft dat de forse import van suiker (denk aan de Verenigde Oost-Indische Companie - VOC!) naar de haven van Amsterdam gepaard ging met een sterke toename van het aantal gevallen van niet alleen tandbederf (cariës) en obesitas (overgewicht), maar ook van jicht. Vandaar mijn advies geen of althans minder bier, frisdrank of vruchtensap te gebruiken, doch $u$ te beperken tot SPA. 
Tot slot enkele woorden van dank.

Eerst aan de Koninklijke Marine. Zonder reddingshelikopter tijdens wadlopen zouden meerdere hier aanwezige persoon niet of niet meer bestaan en was er nooit sprake geweest van deze afscheidsrede (Televisie Journaal 27 mei 1978). "Die eine entscheidende Sekunde" (Stefan Zweig). Uiteraard gelden woorden van dank mijn ouders en leermeesters, met name de collegae Cats en Valkenburg. Voorts Asim Khan (die mij leerde medische artikelen te schrijven), Hans-Ueli Rentsch voor zijn hulp bij de Schweizerische Familienstudie Morbus Bechterew.

Het geldt evenzeer voor de huidige en voormalige staf en medewerkers van onze afdeling. Namen noem ik niet. Ik ga vergeten mensen te noemen. Ik heb het volste vertrouwen in mijn opvolgsters Annelies Boonen en Debby Vosse. Vrouwen-Power!

De opleiding tot reumatoloog is nu onder Debby al beter dan die ooit was onder mijn verantwoordelijkheid en de AlOs profiteren ten volle van de betrokkenheid, diepgang en deskundigheid van Annelies.

Coen Stehouwer, afdelingshoofd voor Interne Geneeskunde, MDL en Reumatologie. Het liefst zou ik nu niets zeggen. Elk woord is een onderwaardering voor mijn waardering en respect voor jouw inzet, persoonlijke betrokkenheid en gevoel voor rechtvaardigheid. Jij bent terecht een grootmeester. Dank voor de steun in een moeilijke periode.

Dank aan de leden van de Raad van Bestuur MUMC voor alle blijken van vertrouwen en voor de efficiëntie samenwerking.

Heel veel dank aan al mijn patiënten. Ik heb veel van u geleerd. Ik dank $\mathrm{u}$ voor uw vertrouwen. Ik heb steeds getracht uw leidsman te zijn en $u$ te behoeden voor onnodige risico's, doch tegelijk getracht waar mogelijk uw lot te verbeteren. De therapeutische mogelijkheden daartoe nemen momenteel jaarlijks toe. Als ik een wens mag uitspreken, dan is dat de volgende. Laat in de toekomst de arts-patient relatie gebaseerd blijven op wederzijds vertrouwen en respect. Laten wij verre blijven van een financieel gestuurde arts-cliënt relatie.

Ik vrees dat mij hierna enige dank toegezwaaid gaat worden. Bedenk echter het volgende. Achter menig man staat een sterke vrouw. Dat geldt ook voor mij. Zij was het die mijn inzet voor $u$ tolereerde en zelfs actief ondersteunde: "mede mogelijk gemaakt door Hermine".

Ik heb gezegd. 
